\title{
Clinical characteristics and prognosis of bacteraemia during postoperative intra- abdominal infections
}

Adel Alqarni ${ }^{1,2}$, Elie Kantor ${ }^{1,3}$, Nathalie Grall ${ }^{4,5}$, Sebastien Tanaka ${ }^{1,6}$, Nathalie Zappella ${ }^{1}$, Mathieu Godement ${ }^{1}$, Lara Ribeiro-Parenti ${ }^{3,7}$, Alexy Tran-Dinh ${ }^{1,3,8}$ and Philippe Montravers ${ }^{1,3,9^{*}}$ (1)

\begin{abstract}
Background: Bloodstream infections of abdominal origin are usually associated with poor prognosis. We assessed the clinical and microbiological characteristics of critically ill patients admitted to the intensive care unit (ICU) for postoperative intra-abdominal infection (PIAI) and analysed the influence of bacteraemia on their outcome.

Methods: All consecutive PIAI patients admitted to the ICU between 1999 and 2014 were prospectively analysed. Bacteraemic patients (at least one positive blood culture in the $24 \mathrm{~h}$ preceding/following surgery) were compared with non-bacteraemic patients. Demographic characteristics, underlying disease, severity scores at the time of reoperation, microbiological results, therapeutic management, outcome, and survival were recorded. Results are expressed as median (interquartile range (IQR)) or proportions.

Results: Overall, 343 patients (54\% male, 62 (49-73) years old) with PIAl were analysed, including 64 (19\%) bacteraemic patients. Immunosuppression and cancer were more frequent in bacteraemic patients $(p<0.001$ in both cases). No difference between groups was observed for the characteristics of initial surgery. Time to reoperation, site, and cause of PIAI were similar in both groups. At the time of reoperation, Sequential Organ Failure Assessment (SOFA) score was higher in bacteraemic patients (8 (6-10) versus 7 (4-10); $p<0.05)$. A predominance of Gram-positive (34\%) and Gram-negative (47\%) bacteria were recovered from blood cultures (polymicrobial bacteraemia in $9(14 \%)$ patients and bacteraemia involving multidrug-resistant organisms in 14 (22\%) patients). In multivariate analysis, risk factors for bacteraemia were immunosuppression or cancer, high SOFA score, and E. coli in peritoneal samples. Bacteraemia did not impact the management (with similar results for the adequacy of antibiotic therapy, anti-infective agents used, de-escalation or duration of therapy in both groups). Neither hospital mortality nor morbidity criteria differed between groups. Risk factors for mortality in multivariate analysis were urgent initial surgery, high Simplified Acute Physiology Score (SAPS) II score and documented antifungal therapy, but not perioperative bacteraemia.
\end{abstract}

Conclusions: In this ICU population, bacteraemia did not change the overall management of patients with PIAI. Our data suggest that bacteraemic patients do not require a specific management.

Keywords: Intra-abdominal infection, Postoperative infection, Bacteraemia, Outcome

\footnotetext{
* Correspondence: philippe.montravers@aphp.fr

${ }^{1}$ Département d'Anesthésie-Réanimation, CHU Bichat-Claude Bernard, APHP,

Paris, France

${ }^{3}$ Université Paris Diderot, Press Sorbonne Cité, Paris, France

Full list of author information is available at the end of the article
}

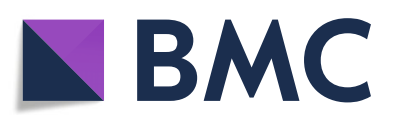

(c) The Author(s). 2018 Open Access This article is distributed under the terms of the Creative Commons Attribution 4.0 International License (http://creativecommons.org/licenses/by/4.0/), which permits unrestricted use, distribution, and reproduction in any medium, provided you give appropriate credit to the original author(s) and the source, provide a link to the Creative Commons license, and indicate if changes were made. The Creative Commons Public Domain Dedication waiver (http://creativecommons.org/publicdomain/zero/1.0/) applies to the data made available in this article, unless otherwise stated. 


\section{Background}

Bacteraemia is a major cause of morbidity and mortality in critically ill patients [1-3], defined as primary when no source of infection is identified or secondary to dissemination of pathogens from other sites of infection [4]. One of the most common causes of secondary bacteraemia is intra-abdominal infection, accounting for $11-15 \%$ of all secondary cases in critically ill patients $[4,5]$.

Bacteraemia secondary to intra-abdominal surgical site infection is not uncommon, with a reported incidence of $10-26 \%$ at the time of reoperation $[6,7]$ and increased rates in the case of delayed diagnosis [8], septic shock [6], or multidrug-resistance [9]. Patients who develop postoperative intra-abdominal infection (PIAI) are at higher risk of adverse outcome and mortality. Interestingly, no specific data are available in the literature concerning bacteraemia during PIAI. In a retrospective single-centre cohort study of 96 critically ill patients, De Waele et al. found that the mortality of patients with bacteraemia of abdominal origin was high (62.5\%) and higher than the Acute Physiology and Chronic Health Evaluation (APACHE) II-based expected mortality rate [10]. These investigators found that older age and renal failure were independent risk factors of death. However, only $39 \%$ of their population had secondary peritonitis and the proportion of PIAI cases was not specified.

Another controversial issue concerns the duration of antibiotic therapy in bacteraemic patients. Prolonged therapy has been reported in patients treated for bacteraemia [11], which can be explained by the fear of increased treatment failure rates in the case of short-course antibiotic therapy [12]. However, insufficient evidence is available in patients with peritonitis.

The objective of this study was to analyse the impact of bacteraemia on morbidity and mortality in critically ill PIAI patients. We hypothesised that outcome is determined by both clinical and microbiological factors in this population.

\section{Methods \\ Study population}

Between January 1999 and December 2014, all consecutive intensive care unit (ICU) patients admitted to our surgical ICU for management of a first episode of PIAI were prospectively included in a database. This observational study was conducted according to the terms and regulations of the local institutional review boards (CEER CHU Bichat, Paris Diderot University, Paris, agreement 10-008). According to French Law, no informed consent was required since this observational study did not modify the physician's treatment decisions.

\section{Data collection}

Bacteraemic patients were defined as having at least one positive blood culture in the $24 \mathrm{~h}$ preceding or following surgery for PIAI. In case of positive blood culture for coagulase-negative staphylococci (CNS), two positive blood cultures with the same microorganism and the same antibiotic susceptibility were required to establish the diagnosis of bacteraemia or one positive blood culture matching the same microorganism with the same antibiotic susceptibility in the peritoneal samples. Medical charts were retrospectively reviewed. Demographic characteristics, underlying medical conditions, and their severity according to the McCabe score [13] were recorded. The type of initial surgery and presence of antimicrobial therapy prior to PIAI surgery were also recorded. Anatomical location above or below the transverse mesocolon and source of PIAI were noted.

Severity scores (Simplified Acute Physiology Score (SAPS) II and Sequential Organ Failure Assessment (SOFA) scores) were obtained at the time of reoperation for PIAI [14, 15]. Temperature, white blood cell counts, serum creatinine, and SOFA score were assessed on the day of reoperation (day 0) and at days 3 and 7 after surgery for patients still in the ICU. Differences (delta) between the SOFA scores observed on day 3 and day 0 were calculated. Patients meeting the following three criteria on day 3 were arbitrarily defined as improving: SOFA score $\leq 3$ points, white blood cell counts $\geq 5000$ and $\leq 15,000$ cells $/ \mathrm{mm}^{3}$, and temperature $\geq 36{ }^{\circ} \mathrm{C}$ and $\leq 38{ }^{\circ} \mathrm{C}$. Similar analyses were performed at day 7 to compare changes in these criteria between day 7 and day 0 .

\section{Microbiological examinations}

Blood cultures were systematically collected during the management of PIAI. All blood culture bottles were handled using the laboratory's blood culture system (BD BACTEC ${ }^{\mathrm{m}}$; Becton-Dickinson). Positive blood cultures drawn within $24 \mathrm{~h}$ before and after reoperation for PIAI were noted. Diagnostic procedures on all positives bottles included Gram stain and bacterial isolation and identification using standard bacteriology techniques. The antibiotic susceptibility of each strain was determined using the disk diffusion method (http://www.sfm-microbiologie.org).

Peritoneal fluid samples were systematically collected during surgery and were immediately sent to the bacteriology laboratory. Samples were processed according to the laboratory's standard methods. Plates were incubated for $48 \mathrm{~h}$ at $35^{\circ} \mathrm{C}$. All morphologically distinct colonies were identified and tested for antibacterial susceptibility by the disk diffusion method (http://www.sfm-microbiologie.org) [7]. Multidrug-resistant (MDR) bacteria were defined as those resistant to three or more antimicrobial classes [16].

\section{Anti-infective therapy}

Empirical antibiotic therapy (EAT) was started at the time of reoperation for PIAI. The choice of therapy took 
into account the severity of the case, previous antibiotic therapies, and local epidemiology. According to French guidelines, EAT included a combination of broadspectrum beta-lactams such as piperacillin/tazobactam or imipenem/cilastatin associated with aminoglycosides and vancomycin [17]. EAT, changes at the time of documented therapy including escalation and de-escalation, and total duration of therapy were recorded [7]. Empirical antifungal agents were administered when a high risk of fungal infection was suspected and adapted to the identification results of peritoneal samples $[17,18]$.

\section{Outcome}

The primary outcome was ICU mortality from any cause. Medical and surgical complications, suspicion of persistent sepsis $[19,20]$, additional reoperations for persistence of the initial infection or superinfections (including MDR bacteria), and death between the day following surgery and discharge from hospital were assessed. Duration of ICU stay and mechanical ventilation were also assessed.

\section{Statistical analysis}

Results are expressed as median and interquartile range (IQR) or number and proportions. Statistical analysis was performed with SAS@ 9.4 (SAS Institute, Cary, NC, USA). Comparisons between bacteraemic and non-bacteraemic patients used Chi-square test and Fisher's exact test for discrete variables and unpaired Wilcoxon tests for quantitative variables. Risk factors for bacteraemia and death were assessed by univariate analysis and unadjusted odds ratio (OR) and 95\% confidence intervals (CIs) were calculated. Variables with $p$ values less than 0.15 in univariate analysis were introduced as dependent factors into two multivariate logistic regression analyses using a stepwise selection method, and the collinearity between predictors was analysed. Bacteraemia constituted the outcome of the first model, and ICU mortality constituted the outcome of the second model. Bacteraemia was forced in the model of ICU mortality as our primary factor of interest until the end of the selection process. In addition, the year of inclusion was forced in both analyses to take the time effect into account. Logistic models were evaluated for discrimination with the $\mathrm{C}$-statistic and for calibration with the Hosmer-Lemeshow test.

\section{Results}

\section{Patient characteristics}

Overall, 343 PIAI patients including 64 (19\%) bacteraemic patients were analysed. The demographic characteristics and underlying diseases at the time of diagnosis were similar in both groups, except for increased proportions of immunosuppression and cancer in bacteraemic patients (Table 1). Surgical characteristics were similar in both groups, while bacteraemic patients were slightly more severe at the time of diagnosis as illustrated by the SOFA score (Table 1). The median SAPS II score slowly increased from 46.0 in 1999 to 54.0 in 2014.

\section{Microbiological results}

Overall, 102 positive blood cultures were collected in bacteraemic patients, yielding 64 microorganisms with a median of 1 (range 1-8) positive blood cultures per patient (Table 2): 21 (33\%) patients with aerobic Gram-positive bacteraemia, $30(47 \%)$ patients with aerobic Gram-negative bacteraemia, 10 (16\%) patients with anaerobic bacteraemia, and $6(9 \%)$ patients with fungaemia. Polymicrobial bacteraemia was observed in $9(14 \%)$ cases (including 2 aerobic Gram-negative organisms $(n=2), 2$ aerobic Gram-positive organisms $(n=1), 2$ anaerobes $(n=2)$, and 2 fungi $(n=1))$. Among these organisms, 14 bacteraemic patients had MDR bacteria: 6 Gram-positive bacteria (3 methicillin-resistant CNS, 1 methicillin-resistant $S$. aureus, and 2 E. faecium) and 8 Gram-negative bacteria (6 ESBL or AmpC-producing Enterobacteriaceae, and 2 Pseudomonas spp). Among the microorganisms isolated from blood culture, 29 organisms in 27 patients were not isolated from surgical operative samples: E. coli $n=4$, Enterobacter spp. $n=1$, Pseudomonas spp. $n=3$, enterococci $n=1$, streptococci $n=4$, CNS $n=1$, S. aureus $n=3$, and anaerobes $n=10$.

A total of 1022 microorganisms were isolated from peritoneal surgical samples (Table 2). Polymicrobial peritoneal cultures were reported in 58/64 (91\%) bacteraemic and 228/279 (82\%) non-bacteraemic patients, respectively $(p=0.09)$. The frequency of bacteraemia was increased in patients with Enterobacteriaceae, E. coli, and $E$. faecalis isolated from peritoneal samples (OR 2.25, 95\% CI 1.12-4.52, $p=0.022$; OR 2.12, 95\% CI 1.22-3.70], $p=0.007$; and OR 1.98, 95\% CI 1.12-3.52, $p=0.019$; respectively). The proportions of MDR bacteria cultured from peritoneal samples were similar between bacteraemic and non-bacteraemic patients (26 (41\%) versus $113(41 \%)$ patients, respectively; $p=0.50)$.

\section{Risk factors for bacteraemia}

The risk factors for bacteraemia identified in univariate analysis are presented in Table 3. In multivariate analysis, after adjustment for the year of inclusion, we identified three risk factors independently associated with an increased risk of bacteraemia: immunosuppression or cancer, SOFA score at the time of reoperation, and $E$. coli isolated from surgical peritoneal samples (Table 3).

\section{Anti-infective therapy}

Empirical therapy did not differ between groups (Table 4). Similar proportions of adequacy of EAT were achieved in both groups. At the time of documented therapy, proportions of escalation, de-escalation, and combination therapy 
Table 1 Characteristics and clinical findings of patients with positive blood cultures and patients without bacteraemia

\begin{tabular}{|c|c|c|c|c|c|c|}
\hline Variables & $\begin{array}{l}\text { All patients } \\
(n=343)\end{array}$ & $\begin{array}{l}\text { Bacteraemic patients } \\
(n=64)\end{array}$ & $\begin{array}{l}\text { Patients without } \\
\text { bacteraemia }(n=279)\end{array}$ & Odds ratio & $95 \% \mathrm{Cl}$ & $p$ value \\
\hline \multicolumn{7}{|c|}{ Demographic characteristics and underlying diseases } \\
\hline Age (years), median (IQR) & $62(49-73)$ & $63(52-74)$ & $61(48-73)$ & 0.92 & $(0.53-1.58)$ & 0.56 \\
\hline Male gender, $n(\%)$ & $184(54)$ & $32(50)$ & $152(54)$ & 0.83 & $(0.49-1.44)$ & 0.52 \\
\hline Fatal underlying disease, $n(\%)$ & $110(32)$ & $29(45)$ & $81(29)$ & 2.02 & $(1.16-3.53)$ & 0.012 \\
\hline Immunosuppression, $n(\%)$ & $121(35)$ & $37(59)$ & $84(30)$ & 3.25 & $(1.85-5.71)$ & $<0.001$ \\
\hline Diabetes mellitus, $n(\%)$ & $59(17)$ & $12(19)$ & $47(17)$ & 1.14 & $(0.56-2.29)$ & 0.72 \\
\hline Cancer, $n(\%)$ & $126(37)$ & $35(55)$ & $91(33)$ & 2.49 & $(1.43-4.33)$ & $<0.001$ \\
\hline \multicolumn{7}{|l|}{ Initial surgery } \\
\hline Upper gastrointestinal tract surgery, $n(\%)$ & $150(44)$ & $26(41)$ & $124(44)$ & 0.85 & $(0.49-1.48)$ & 0.57 \\
\hline Septic or contaminated surgery, n (\%) & $123(36)$ & $25(42)$ & $98(37)$ & 1.20 & $(0.68-2.12)$ & 0.53 \\
\hline Emergency procedure, $n(\%)$ & $135(39)$ & $22(34)$ & $113(41)$ & 0.77 & $(0.43-1.35)$ & 0.37 \\
\hline Antibiotics before reoperation for PIAI, $n$ (\%) & $215(63)$ & $43(67)$ & $172(62)$ & 1.25 & $(0.70-2.22)$ & 0.45 \\
\hline $\begin{array}{l}\text { Interval between initial surgery and } \\
\text { reoperation (days), median (IQR) }\end{array}$ & $7(4-12)$ & $8(4-15)$ & $7(4-11)$ & 1.09 & $(0.63-1.89)$ & 0.25 \\
\hline \multicolumn{7}{|l|}{ Severity criteria at the time of reoperation } \\
\hline SAPS II score, median (IQR) & $47(35-59)$ & $50(38-63)$ & $47(34-58)$ & 0.89 & $(0.52-1.54)$ & 0.076 \\
\hline SOFA score, median (IQR) & $8(4-10)$ & $8(6-10)$ & $7(4-10)$ & 1.10 & $(0.59-1.75)$ & 0.034 \\
\hline Haemodynamic failure ${ }^{\mathrm{a}}, n(\%)$ & $224(65)$ & $46(73)$ & $178(64)$ & 1.53 & $(0.83-2.81)$ & 0.16 \\
\hline Respiratory failure ${ }^{a}, n(\%)$ & $154(45)$ & $30(48)$ & $124(44)$ & 1.13 & $(0.65-1.96)$ & 0.65 \\
\hline Renal failure ${ }^{a}, n(\%)$ & $83(24)$ & $16(25)$ & $67(24)$ & 1.05 & $(0.56-1.98)$ & 0.86 \\
\hline \multicolumn{7}{|c|}{ Source of postoperative peritonitis and surgical observations } \\
\hline Generalised infection, $n$ (\%) & $79(23)$ & $20(31)$ & $59(21)$ & 1.69 & $(0.92-3.09)$ & 0.08 \\
\hline Gastroduodenal source of infection, $n(\%)$ & $74(22)$ & $11(17)$ & $63(23)$ & 0.71 & $(0.35-1.44)$ & 0.34 \\
\hline Small bowel source of infection & $88(26)$ & $13(20)$ & $75(27)$ & 0.69 & $(0.35-1.34)$ & 0.27 \\
\hline Colonic or rectal source of infection, $n(\%)$ & $97(28)$ & $20(31)$ & $77(28)$ & 1.19 & $(0.66-2.15)$ & 0.56 \\
\hline Anastomotic leak, $n(\%)$ & $118(34)$ & $25(40)$ & $93(33)$ & 1.31 & $(0.74-2.29)$ & 0.34 \\
\hline Bowel perforation, $n$ (\%) & $119(35)$ & $16(25)$ & $103(37)$ & 0.57 & $(0.30-1.05)$ & 0.07 \\
\hline Abscesses, $n(\%)$ & $61(18)$ & $15(23)$ & $46(16)$ & 1.55 & $(0.80-2.99)$ & 0.19 \\
\hline No demonstrated cause, $n(\%)$ & $49(14)$ & $11(17)$ & $38(14)$ & 1.31 & $(0.63-2.74)$ & 0.46 \\
\hline
\end{tabular}

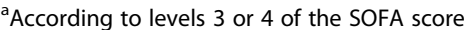

$\mathrm{Cl}$ confidence interval, IQR interquartile range, SAPS Simplified Acute Physiology Score, SOFA Sequential Organ Failure Assessment

for the targeted therapy were not different between groups. In addition, the median duration of therapy was not different between groups (Table 4).

In the group of bacteraemic patients, empirical therapy did not adequately target all bloodstream microorganisms in $11(17 \%)$ cases. The organisms most frequently not adequately treated were methicillin-resistant CNS $(n=5)$, penicillinase-producing Enterobacteriaceae $(n=2)$, Candida spp. $(n=2)$, and E. faecium $(n=1)$. Interestingly, 8 of these patients also had inadequate therapy for peritoneal pathogens.

\section{Patient outcome and risk factors of death}

Comparison of the clinical characteristics of bacteraemic patients and those without positive blood cultures did not reveal any significant difference on day 3 and day 7 (Table 5). A trend toward increased ICU mortality rate was observed in bacteraemic patients $(p=0.08)$.

The mortality rate was similar in bacteraemic patients with MDR bacteraemia and those without MDR bacteraemia $(5 / 15(33 \%)$ versus $22 / 49(45 \%) ; p=0.55)$. Moreover, similar proportions of medical and surgical complications were observed in both groups. Mortality was observed in $3 / 6(50 \%)$ cases of fungaemia versus $23 / 58(40 \%)$ of the other bacteraemic patients $(p=0.68)$. No significant difference in terms of outcome was observed between the 11 bacteraemic patients who did not receive adequate EAT against bloodstream isolates versus the adequately treated cases: persistent intra-abdominal sepsis in $7(64 \%)$ versus $31(58 \%), p=1$; one or more 
Table 2 Microbiological results of peritoneal samples and antimicrobial therapy in bacteraemic and non-bacteraemic patients

\begin{tabular}{|c|c|c|c|}
\hline \multirow[t]{2}{*}{ Microbiological results } & \multicolumn{2}{|c|}{ Bacteraemic patients $(n=64)$} & \multirow{2}{*}{$\begin{array}{l}\text { Patients without bacteraemia }(n=279 \\
\text { Surgical samples }\end{array}$} \\
\hline & Blood cultures & Surgical samples & \\
\hline Total number of microorganisms & 75 & 215 & 807 \\
\hline Gram-negative aerobic bacteria, $n(\%)$ & $32(43)$ & $97(45)$ & $312(39)$ \\
\hline Enterobacteriaceae, n (\%) & $27(36)$ & $86(40)$ & $254(31)$ \\
\hline Escherichia coli, n (\%) & $13(17)$ & $42(20)$ & $124(15)$ \\
\hline Klebsiella spp., $n(\%)$ & $3(4)$ & $10(5)$ & $34(4)$ \\
\hline Enterobacter spp., $n(\%)$ & $8(11)$ & $17(8)$ & $44(5)$ \\
\hline Other Enterobacteriaceae, $n(\%)$ & $3(4)$ & $17(8)$ & $52(6)$ \\
\hline Non-fermenting Gram-negative bacteria, $n(\%)$ & 40 & $10(5)$ & $44(5)$ \\
\hline Pseudomonas aeruginosa, $n(\%)$ & $3(4)$ & $9(4)$ & $39(5)$ \\
\hline Miscellaneous Gram-negative bacilli, $n$ (\%) & $1(1)$ & $1(0.5)$ & $14(2)$ \\
\hline Gram-positive aerobic bacteria, $n(\%)$ & $22(29)$ & $73(34)$ & $308(38)$ \\
\hline Staphylococcus aureus, n (\%) & $5(7)$ & $4(2)$ & $26(3)$ \\
\hline Coagulase-negative staphylococci, $n$ (\%) & $5(7)$ & $8(4)$ & $50(6)$ \\
\hline Streptococcus spp., $n$ (\%) & $8(11)$ & $21(10)$ & $75(9)$ \\
\hline Enterococcus spp., $n$ (\%) & $3(4)$ & $38(18)$ & $151(19)$ \\
\hline Miscellaneous Gram-positive cocci, $n$ (\%) & $1(1)$ & $2(1)$ & $6(1)$ \\
\hline Anaerobic bacteria, $n$ (\%) & $14(19)$ & $22(10)$ & $76(9)$ \\
\hline Bacteroides spp., $n$ (\%) & $12(16)$ & $18(8)$ & $46(6)$ \\
\hline Other anaerobes, $n(\%)$ & $2(3)$ & $4(2)$ & $30(4)$ \\
\hline Multidrug-resistant bacteria, $n(\%)$ & $14(19)$ & $26(12)$ & $113(14)$ \\
\hline Fungi, $n(\%)$ & $7(9)$ & $23(11)$ & $110(14)$ \\
\hline Candida albicans, $n$ (\%) & $3(4)$ & $13(6)$ & $71(9)$ \\
\hline Non-albicans Candida spp., n (\%) & $3(4)$ & $9(4)$ & $32(4)$ \\
\hline
\end{tabular}

Proportions calculated as number of isolates

Table 3 Risk factors for bacteraemia in univariate and multivariate analysis

\begin{tabular}{|c|c|c|c|c|c|c|}
\hline \multirow[b]{2}{*}{ Variables } & \multicolumn{3}{|c|}{ Univariate analysis } & \multicolumn{3}{|l|}{ Multivariable analysis } \\
\hline & Odds ratio & $95 \% \mathrm{Cl}$ & $p$ value & Adjusted odds ratio & $95 \% \mathrm{Cl}$ & $p$ value \\
\hline \multicolumn{7}{|l|}{ Demographic characteristics and underlying diseases } \\
\hline Fatal underlying disease & 2.02 & $(1.16-3.53)$ & 0.012 & & & \\
\hline Cancer or immunosuppression & 2.64 & $(1.51-4.62)$ & $<0.001$ & 2.59 & $(1.46-4.59)$ & 0.001 \\
\hline \multicolumn{7}{|l|}{ Severity criteria at the time of reoperation } \\
\hline SOFA score ${ }^{a}$ & 1.10 & $(0.59-1.75)$ & 0.034 & $1.19^{\mathrm{a}}$ & $(1.02-1.39)$ & 0.002 \\
\hline \multicolumn{7}{|c|}{ Source of postoperative peritonitis and surgical observations } \\
\hline Generalised peritonitis & 1.69 & $(0.92-3.09)$ & 0.08 & & & \\
\hline Interval between initial surgery and reoperation ${ }^{a}$ & 1.02 & $0.98-1.05$ & 0.247 & & & \\
\hline \multicolumn{7}{|l|}{ Microbiological results of peritoneal surgical samples } \\
\hline Enterobacteriaceae $^{\mathrm{b}}$ & 2.52 & $(1.23-5.20)$ & 0.010 & & & \\
\hline Escherichia colib & 2.13 & $(1.22-3.71)$ & 0.008 & 2.10 & $(1.19-3.73)$ & 0.011 \\
\hline
\end{tabular}

The model was adjusted on year of admission

Multivariate logistic regression with stepwise selection: the C-index of the model was $0.6995 \% \mathrm{Cl} 0.61-0.77$ and the Hosmer-Lemeshow test $p$ value was 0.377 $\mathrm{Cl}$ confidence interval, SOFA Sequential Organ Failure Assessment

aper 1 day

${ }^{\mathrm{b}}$ Per 2 points 
Table 4 Empirical and documented therapies in bacteraemic and non-bacteraemic patients

\begin{tabular}{|c|c|c|c|}
\hline Anti-infective regimens & $\begin{array}{l}\text { Bacteraemic } \\
\text { patients } \\
(n=64)\end{array}$ & $\begin{array}{l}\text { Patients without } \\
\text { bacteraemia } \\
(n=279)\end{array}$ & $p$ value \\
\hline \multicolumn{4}{|l|}{ Empirical therapy } \\
\hline Combination of EAT, n (\%) & $49(77)$ & $226(81)$ & 0.42 \\
\hline Imipenem/cilastatin, $n$ (\%) & $22(34)$ & $69(25)$ & 0.12 \\
\hline Piperacillin tazobactam, n (\%) & $36(56)$ & $173(62)$ & 0.39 \\
\hline Vancomycin, $n(\%)$ & $30(47)$ & $122(44)$ & 0.65 \\
\hline Aminoglycosides, $n(\%)$ & $31(48)$ & $140(50)$ & 0.80 \\
\hline Antifungals, $n(\%)$ & $21(33)$ & $101(36)$ & 0.61 \\
\hline Fluconazole, $n(\%)$ & $17(27)$ & $89(32)$ & 0.45 \\
\hline Caspofungin, $n(\%)$ & $3(5)$ & $8(3)$ & 0.43 \\
\hline Adequacy of EAT, $n(\%)$ & $43(67)$ & $190(68)$ & 0.89 \\
\hline \multicolumn{4}{|l|}{ Documented therapy } \\
\hline $\begin{array}{l}\text { Antibiotic treatment } \\
\text { de-escalation, } n(\%)\end{array}$ & $37(58)$ & $163(58)$ & 0.93 \\
\hline $\begin{array}{l}\text { Antibiotic treatment } \\
\text { escalation, } n(\%)\end{array}$ & $15(23)$ & $72(26)$ & 0.69 \\
\hline Combination of EAT, $n(\%)$ & $38(59)$ & $190(68)$ & 0.19 \\
\hline Imipenem/cilastatin, $n$ (\%) & $23(36)$ & $56(20)$ & 0.007 \\
\hline Piperacillin tazobactam, n (\%) & $20(31)$ & $98(35)$ & 0.55 \\
\hline Vancomycin, $n(\%)$ & $16(25)$ & $90(32)$ & 0.25 \\
\hline Aminoglycosides, n (\%) & $12(19)$ & $36(13)$ & 0.22 \\
\hline Antifungals, $n(\%)$ & $20(31)$ & $117(42)$ & 0.11 \\
\hline Fluconazole, $n(\%)$ & $16(25)$ & $104(37)$ & 0.06 \\
\hline Caspofungin, $n(\%)$ & $2(3)$ & $7(3)$ & 0.78 \\
\hline $\begin{array}{l}\text { Duration of antibiotic therapy } \\
\text { in days }{ }^{a} \text {, median (IQR) }\end{array}$ & $10(8-14)$ & $10(8-14)$ & 0.89 \\
\hline
\end{tabular}

EAT Empirical antibiotic therapy, IQR interquartile range

${ }^{a}$ Variable measured in surviving patients

reoperations in $4(36 \%)$ versus $26(49 \%), p=0.52$; and death in the ICU in 6 (55\%) versus $21(40 \%), p=0.50$.

The risk factors for mortality identified in univariate analysis are presented in Table 6. In multivariate analysis, after adjustment for the year of inclusion and the presence of bacteraemia, the following factors were independently associated with a higher mortality rate: urgent initial surgery $(p=0.0003)$, SAPS II $>47$ at the time of reoperation $(p<0.0001)$, and empirical antifungal therapy $(p=0.002)$, while de-escalation of documented therapy $(p=0.003)$ had a protective role.

\section{Discussion}

In this single-centre cohort study of patients with PIAI, the incidence of perioperative bacteraemia was $19 \%$. A trend toward increased mortality rate in bacteraemic patients was observed compared with non-bacteraemic patients, with no major changes in morbidity criteria. The factors associated with bacteraemia were the presence of immunosuppression, ongoing cancer, and high SOFA score. The microorganisms isolated from the surgical site did not differ between bacteraemic and non-bacteraemic patients except for an increased proportion of $E$. coli in bacteraemic patients. Adequate empirical antimicrobial therapy rates and duration of antibiotic therapy did not differ between bacteraemic and non-bacteraemic patients. High severity scores, initial emergency surgery, and antifungal therapy were independent risk factors for mortality in multivariate analysis.

Few data are available assessing the clinical consequences of secondary bloodstream infections in peritonitis. Most of the published reports do not distinguish community-acquired infections from healthcare-associated infections. During bacteraemia in surgical ICU patients, the factors associated with poor prognosis are the severity of acute illness at the onset of bacteraemia, the presence of organ dysfunction, and Gram-negative bacteria or Candida spp. infections [21]. One-third of cases of undiagnosed abdominal septic focus presented breakthrough infection or reappearance of positive blood cultures during antibiotic therapy [22]. Polymicrobial bacteraemia is usually suggestive of intra-abdominal sepsis, but other sites are also associated with several polymicrobial samples [10, 11]. Blood cultures yielding Gram-negative bacilli, enterococci, and anaerobes are indicative of gastrointestinal flora, but staphylococcal bacteraemia is also reported [6-9].

In our cohort, the identified criteria for recognising bacteraemic patients during PIAI were poorly discriminative and did not allow any specific management. As expected, the most severe cases were those at risk of bacteraemia. This point has been previously reported, as bacteraemia associated with intra-abdominal infections appears to be more frequent in patients with septic shock [6]. The size of the inoculum could also be of importance, as suggested by the increased risk of bacteraemia in the case of generalised peritonitis and peritoneal samples yielding E. coli cultures. Severe underlying disease and immunosuppression have been previously described as possible risk factors for bacteraemia, but these criteria were not assessed in surgical postoperative infections.

In our PIAI patients, bacteraemia was associated with limited clinical consequences. Clinical recovery, analysed on day 3 and day 7 after surgery, did not differ between groups. Our data confirm the observations of Havey et al., who reported early improvement of clinical parameters in patients treated for bacteraemia [11]. Our observations suggest an incidental nature of bacteraemia rather than a major threat. This assumption is also confirmed by the absence of any specific morbidity criteria in the postoperative course of bacteraemic patients compared with non-bacteraemic patients. Additional observations, such as the high mortality rates reported in the 
Table 5 Clinical outcome in bacteraemic and non-bacteraemic patients

\begin{tabular}{|c|c|c|c|c|c|}
\hline Clinical outcomes & $\begin{array}{l}\text { Bacteraemic patients } \\
(n=64)\end{array}$ & $\begin{array}{l}\text { Patients without } \\
\text { bacteraemia }(n=279)\end{array}$ & Odds ratio & $95 \% \mathrm{Cl}$ & $p$ value \\
\hline \multicolumn{6}{|l|}{ On day 3 after surgery for PIAI } \\
\hline Temperature $\geq 36^{\circ} \mathrm{C}$ and $\leq 38^{\circ} \mathrm{C}, n(\%)$ & $25 / 55(45.4)$ & 165/243 (67.9) & 0.39 & $(0.21-0.71)$ & $<0.01$ \\
\hline WBC count $\geq 5000$ and $\leq 15,000 / \mathrm{mm}^{3}, n(\%)$ & 20/55 (57.1) & 108/243 (44.4) & 0.71 & $(0.39-1.31)$ & 0.27 \\
\hline SOFA score $\leq 3$ points, $n(\%)$ & $22 / 55(40)$ & 104/243 (42.8) & 0.89 & $(0.49-1.62)$ & 0.70 \\
\hline All three criteria, $n(\%)$ & $7 / 55(12.7)$ & $42 / 243(17.3)$ & 0.69 & $(0.29-1.64)$ & 0.54 \\
\hline Delta SOFA between day 3 and day 0, median (IQR) & $1(0-4)$ & $2(0-4)$ & $1.00^{\mathrm{a}}$ & $(0.91-1.11)$ & 0.82 \\
\hline \multicolumn{6}{|l|}{ On day 7 after surgery for PIAI } \\
\hline Temperature $\geq 36{ }^{\circ} \mathrm{C}$ and $\leq 38{ }^{\circ} \mathrm{C}, n(\%)$ & 29/44 (65.9) & $140 / 200(70)$ & 0.82 & $(0.41-1.65)$ & 0.59 \\
\hline WBC count $\geq 5000$ and $\leq 15,000 / \mathrm{mm}^{3}, n(\%)$ & $23 / 44(52.3)$ & $84 / 200(42)$ & 1.51 & $(0.78-2.91)$ & 0.21 \\
\hline SOFA score $\leq 3$ points, $n(\%)$ & $22 / 44(50)$ & $112 / 200(56)$ & 0.78 & $(0.41-1.51)$ & 0.46 \\
\hline All three criteria, $n(\%)$ & $12 / 44(27.3)$ & $44 / 200(22)$ & 1.33 & $(0.63-2.79)$ & 0.45 \\
\hline Delta SOFA between day 7 and day 0, median (IQR) & $3.5(1.2-6)$ & $4(1-6)$ & $0.98^{\mathrm{a}}$ & $(0.89-1.11)$ & 0.93 \\
\hline Suspected persistent sepsis, $n$ (\%) & $36(58)$ & $144(53)$ & 1.21 & $(0.69-2.11)$ & 0.50 \\
\hline Reoperation, $n(\%)$ & $29(45)$ & $122(44)$ & 1.02 & $(0.59-1.76)$ & 0.81 \\
\hline Total number of reoperations, median (IQR) & $1(1-2)$ & $2(1-2)$ & 0.88 & $(0.71-1.10)$ & 0.21 \\
\hline Interval between surgery for PIAI and reoperation, median (IQR) & $5(2.5-7)$ & $5(2-8)$ & 0.97 & $(0.87-1.08)$ & 0.42 \\
\hline \multicolumn{6}{|l|}{ Main reasons for reoperation } \\
\hline Septic shock/multiple organ failure, $n(\%)$ & $11 / 29(38)$ & 47/122 (39) & 0.97 & $(0.42-2.24)$ & 0.95 \\
\hline Sepsis, $n(\%)$ & $18 / 29(62)$ & $75 / 122(62)$ & 1.02 & $(0.44-2.36)$ & 0.95 \\
\hline Haemorrhage, $n$ (\%) & $2 / 29(7)$ & 9/122(7) & 0.93 & $(0.18-4.55)$ & 1 \\
\hline Suspicion of bowel ischaemia, $n(\%)$ & $2 / 29(7)$ & $26 / 122(21)$ & 0.27 & $(0.06-1.22)$ & 0.11 \\
\hline \multicolumn{6}{|l|}{ Main intraoperative diagnoses at reoperation } \\
\hline Anastomotic leak, $n(\%)$ & $8 / 29(28)$ & 29/122 (24) & 1.22 & $(0.48-3.04)$ & 0.64 \\
\hline Bowel perforation, $n$ (\%) & $4 / 29(14)$ & 25/122 (20) & 0.62 & $(0.19-1.94)$ & 0.60 \\
\hline Ischaemia, $n$ (\%) & $2 / 29(7)$ & 23/122 (19) & 0.31 & $(0.07-1.43)$ & 0.17 \\
\hline Abscess or collections, $n(\%)$ & $5 / 29(17)$ & $14 / 122(11)$ & 1.60 & $(0.53-4.89)$ & 0.37 \\
\hline No identified cause, $n(\%)$ & $5 / 29(17)$ & 10/122 (8) & 2.33 & $(0.73-7.44)$ & 0.16 \\
\hline Medical complications, n (\%) & $5(8)$ & $37(14)$ & 0.55 & $(0.20-1.47)$ & 0.29 \\
\hline Duration of mechanical ventilation, median (IQR), days ${ }^{\mathrm{b}}$ & $8(4-15)$ & $7(3-15)$ & 1.45 & $(0.71-2.95)$ & 0.75 \\
\hline ICU stay, median (IQR), days ${ }^{\mathrm{b}}$ & $12(8-23)$ & $15(8-25)$ & 0.96 & $(0.48-1.94)$ & 0.39 \\
\hline Death in ICU, $n(\%)$ & $26(41)$ & $82(29)$ & 1.64 & $(0.94-2.88)$ & 0.08 \\
\hline Death in hospital, $n(\%)$ & $26(41)$ & $88(32)$ & 1.48 & $(0.85-2.59)$ & 0.16 \\
\hline
\end{tabular}

Cl confidence interval, IQR interquartile range, PIAI postoperative intra-abdominal infection, SOFA Sequential Organ Failure Assessment, WBC white blood cell

${ }^{b}$ Variable measured in survivors

case of fungaemia and bacteraemia not targeted by empirical therapy, could be considered to be signals of interest. However, the number of cases was too small to draw any strong conclusions.

A poorer prognosis was expected in the cohort of bacteraemic patients. The $41 \%$ mortality rate in our study confirms the high mortality rate previously reported by De Waele et al. [10]. However, only a trend towards an increased mortality rate was observed in our bacteraemic patients compared with non-bacteraemic patients.
This point was confirmed in univariate analysis, while other well-known factors, such as emergency surgery and initial severity, were identified as risk factors for mortality. Interestingly, the prognosis did not differ in the presence of fungaemia compared with bacteraemia. The small sample size of our cohort clearly affected the validity of these results. Surprisingly, the role of fungaemia in peritonitis cases has been rarely analysed in the literature, while fungaemia is a known factor of poor prognosis in many instances [23, 24]. Nevertheless, 
Table 6 Univariate and multivariate analyses of risk factors of intensive care unit (ICU) death in the study population

\begin{tabular}{|c|c|c|c|c|c|c|}
\hline \multirow[b]{2}{*}{ Parameters } & \multicolumn{3}{|c|}{ Univariate analysis } & \multicolumn{3}{|c|}{ Multivariate analysis } \\
\hline & Odds ratio & $95 \% \mathrm{Cl}$ & $p$ value & Odds ratio & $95 \% \mathrm{Cl}$ & $p$ value \\
\hline \multicolumn{7}{|l|}{ Demographic characteristics and underlying diseases } \\
\hline Age $>62$ years & 2.45 & $(1.55-3.90)$ & $<0.001$ & & & \\
\hline McCabe Fatal & 1.55 & $(0.96-2.49)$ & 0.08 & & & \\
\hline Immunosuppression or cancer & 1.83 & $(1.15-2.92)$ & 0.01 & & & \\
\hline Urgent initial surgery & 2.04 & $(1.29-3.23)$ & 0.002 & 2.71 & $(1.53-4.81)$ & 0.0006 \\
\hline \multicolumn{7}{|l|}{ Severity criteria at the time of reoperation } \\
\hline Small bowel perforation & 1.57 & $(0.95-2.59)$ & 0.07 & & & \\
\hline SAPS $\|>47$ at reoperation & 4.26 & $(2.61-6.94)$ & $<0.001$ & 4.78 & $(2.71-8.45)$ & $<0.0001$ \\
\hline \multicolumn{7}{|l|}{ Blood and peritoneal microbiological results } \\
\hline Bacteraemia & 1.48 & $(0.84-2.59)$ & 0.16 & 1.62 & $(0.81-3.24)$ & 0.169 \\
\hline \multicolumn{7}{|l|}{ Peritoneal samples involving } \\
\hline Enterococci & 1.71 & $(1.08-2.69)$ & 0.019 & & & \\
\hline Non-fermenting Gram-negative Bacteria & 2.01 & $(1.13-3.65)$ & 0.019 & & & \\
\hline Streptococci & 0.54 & $(0.30-0.96)$ & 0.037 & & & \\
\hline \multicolumn{7}{|l|}{ Empirical and documented therapies } \\
\hline Empirical imipenem therapy & 1.66 & $(1.01-2.72)$ & 0.044 & & & \\
\hline Empirical vancomycin therapy & 1.56 & $(0.99-2.46)$ & 0.050 & & & \\
\hline Empirical antifungal therapy & 1.72 & $(1.08-2.74)$ & 0.019 & 2.91 & $(1.62-5.22)$ & 0.0003 \\
\hline De-escalation documented therapy & 0.54 & $(0.34-0.85)$ & 0.007 & 0.50 & $(0.28-0.89)$ & 0.018 \\
\hline Documented therapy using piperacillin/tazobactam & 1.74 & $(1.09-2.78)$ & 0.018 & & & \\
\hline Documented antifungal therapy & 1.67 & $(1.05-2.63)$ & 0.026 & & & \\
\hline
\end{tabular}

The model was adjusted on year of admission

Multivariate logistic regression with stepwise selection: the C-index for the model was $0.8195 \% \mathrm{Cl} 0.76-0.86$, the Hosmer-Lemeshow test $p$ value was 0.02

$\mathrm{Cl}$ confidence interval, SAPS Simplified Acute Physiology Score

fungal infection might play a role in the prognosis, as indirectly reflected by documented antifungal therapy which was a strong criterion of poor prognosis in our cohort.

The need to treat all isolated microorganisms in these high-risk ICU patients is a subject of debate. Recently published guidelines have failed to address this issue $[17,25,26]$. The usual rule is to target all pathogens isolated from both blood and surgical samples. However, the pathogenic role of certain microorganisms such as staphylococci is debated. Some data suggest a pathogenic role of S. aureus [27]. On the contrary, the role of CNS as a contaminant on blood or surgical samples remains much more controversial. In order to limit the risk of contamination, we used strict selection rules for CNS bacteraemia and we assume that the selected isolates represent authentic pathogens. By means of these criteria, CNS represented only a limited proportion of the organisms isolated from bacteraemic patients. Among the 11 bacteraemic patients in whom empirical anti-infective therapy did not target all bloodstream microorganisms, almost half of the cases involved CNS. Interestingly, the outcome of these cases was not completely favourable, suggesting that discarding these microorganisms may have clinical consequences.

The duration of anti-infective therapy was not different between patients with and without bacteraemia. The optimal duration of antibiotic therapy for bacteraemia during intra-abdominal infections is unknown. In our study, antibiotic therapy for bacteraemic PIAI was administered for $11 \pm 6$ days, a duration usually reported in the literature. Our data suggest that extended therapy is not required in bacteraemic patients. However, this study was not tailored to address this issue and any definitive conclusions would be premature since, in a recent study analysing the benefit of short-course antibiotic therapy in PIAI, we reported an increased risk of postoperative bacteraemia and a higher risk of treatment failure in the case of short-course therapy [28].

Several limitations to the present study must be mentioned, including its retrospective nature. The results of this single-centre analysis may not be directly applicable to other institutions. Breakthrough infections and recurrent bacteraemia could not be assessed due to the short time window for analysis of bacteraemia. The long study duration is also a factor to be taken into account, with 
changing patient characteristics over recent years, with older and more severely ill patients, but the year of inclusion was adjusted for in the multivariate models. The quality of infection source control was not evaluated in this study, although it is an essential element of the prognosis of PIAI patients. The number of reoperations, the reasons for these operations, and the surgical findings did not differ between bacteraemic and non-bacteraemic patients, suggesting that bacteraemia did not play a major role in the outcome.

\section{Conclusion}

In this single-centre observational study, one-fifth of patients had bacteraemia during the early management of PIAI. Bacteraemia was not a risk factor for mortality compared with patients without bacteraemia, and morbidity criteria did not appear to be modified. None of the mortality risk factors identified in our study are susceptible to corrective measures designed to improve the management of these critically ill patients. Increasing the duration of anti-infective therapy could have been proposed to improve the prognosis, although the current trend is to reduce the duration of therapy. Early diagnosis and early management of organ failures and their consequences remain the best rules in the treatment of these patients.

\section{Abbreviations \\ Cl: Confidence interval; CNS: Coagulase-negative staphylococci; EAT: Empirical antibiotic therapy; ICU: Intensive care unit; IQR: Interquartile range; MDR: Multidrug-resistant; OR: Odds ratio; PIAI: Postoperative intra-abdominal infection; SAPS: Simplified Acute Physiology Score: SOFA: Sequential Organ Failure Assessment}

\section{Availability of data and materials}

Data and material kept until the end of 2018 .

\section{Authors' contributions}

Concept and design: PM. Acquisition, analysis or interpretation of data: all authors. Drafting of the manuscript: AA, EK, NG, ATD, PM. Critical revision of the manuscript for important intellectual content: all authors. Statistical analysis: EK, ATD, PM. Administrative, technical or material support: PM. Study supervision: PM. All authors read and approved the final manuscript.

\section{Ethics approval and consent to participate}

This observational study was conducted according to the terms and regulations of the local institutional review boards (CEERB CHU Bichat, Paris Diderot University, Paris, agreement 10-008; CNIL 1413211). According to French Law, no informed consent was required since this observational study did not modify the physician's treatment decisions.

\section{Consent for publication}

Not required.

\section{Competing interests}

The authors declare that they have no competing interests.

\section{Publisher's Note}

Springer Nature remains neutral with regard to jurisdictional claims in published maps and institutional affiliations.

\section{Author details}

'Département d'Anesthésie-Réanimation, CHU Bichat-Claude Bernard, APHP, Paris, France. ${ }^{2}$ King Saud University, Riyadh, Saudi Arabia. ${ }^{3}$ Université Paris Diderot, Press Sorbonne Cité, Paris, France. ${ }^{4}$ Laboratoire de Microbiologie, CHU Bichat-Claude Bernard, APHP, Paris, France. ${ }^{5}$ INSERM UMR 1137, Paris, France. ${ }^{6}$ INSERM UMR 1188, Saint-Denis de la Réunion, France. ${ }^{7}$ Service de Chirurgie Générale, CHU Bichat-Claude Bernard, APHP, Paris, France. ${ }^{8}$ INSERM UMR 1148, Paris, France. ${ }^{9}$ INSERM UMR 1152, Paris, France.

Received: 11 April 2018 Accepted: 19 June 2018

Published online: 07 July 2018

\section{References}

1. Laupland KB, Zygun DA, Davies HD, Church DL, Louie TJ, Doig CJ. Population-based assessment of intensive care unit-acquired bloodstream infections in adults: incidence, risk factors, and associated mortality rate. Crit Care Med. 2002;30:2462-7.

2. Blot S, Vandewoude K, De Bacquer D, Colardyn F. Nosocomial bacteremia caused by antibiotic-resistant gram-negative bacteria in critically ill patients: clinical outcome and length of hospitalization. Clin Infect Dis. 2002;34:1600-6.

3. Vincent JL, Rello J, Marshall J, Silva E, Anzueto A, Martin CD, et al. International study of the prevalence and outcomes of infection in intensive care units. JAMA. 2009:302:2323-9.

4. Tabah A, Koulenti D, Laupland K, Misset B, Valles J, Bruzzi de Carvalho F, et al. Characteristics and determinants of outcome of hospital-acquired bloodstream infections in intensive care units: the EUROBACT international cohort study. Intensive Care Med. 2012;38:1930-45.

5. Boncagni F, Francolini R, Nataloni S, Skrami E, Gesuita R, Donati A, et al. Epidemiology and clinical outcome of healthcare-associated infections: a 4-year experience of an Italian ICU. Minerva Anestesiol. 2015;81:765-75.

6. Riche FC, Dray X, Laisne MJ, Mateo J, Raskine L, Sanson-Le Pors MJ, et al. Factors associated with septic shock and mortality in generalized peritonitis: comparison between community-acquired and postoperative peritonitis. Crit Care. 2009:13:R99.

7. Montravers P, Augustin P, Grall N, Desmard M, Allou N, Marmuse JP, et al. Characteristics and outcomes of anti-infective de-escalation during health care-associated intra-abdominal infections. Crit Care. 2016;20:83.

8. Roehrborn A, Thomas L, Potreck O, Ebener C, Ohmann C, Goretzki PE, et al. The microbiology of postoperative peritonitis. Clin Infect Dis. 2001;33:1513-9.

9. Seguin P, Fedun Y, Laviolle B, Nesseler N, Donnio PY, Malledant Y. Risk factors for multidrug-resistant bacteria in patients with post-operative peritonitis requiring intensive care. J Antimicrob Chemother. 2010;65:342-6.

10. De Waele JJ, Hoste EA, Blot SI. Blood stream infections of abdominal origin in the intensive care unit: characteristics and determinants of death. Surg Infect. 2008;9:171-7.

11. Havey TC, Fowler RA, Pinto R, Elligsen M, Daneman N. Duration of antibiotic therapy for critically ill patients with bloodstream infections: a retrospective cohort study. Can J Infect Dis Med Microbiol. 2013;24:129-37.

12. Nelson AN, Justo JA, Bookstaver PB, Kohn J, Albrecht H, Al-Hasan MN. Optimal duration of antimicrobial therapy for uncomplicated gram-negative bloodstream infections. Infection. 2017:45:613-20.

13. McCabe WR, Jackson GG. Gram-negative bacteremia. I Etiology and ecology. Arch Intern Med. 1962;1 10:847-55.

14. Le Gall JR, Lemeshow S, Saulnier F. A new simplified acute physiology score (SAPS II) based on a European/North American multicenter study. JAMA. 1993;270:2957-63.

15. Vincent JL, Moreno R, Takala J, Willatts S, De Mendonca A, Bruining H, et al. The SOFA (sepsis-related organ failure assessment) score to describe organ dysfunction/failure. On behalf of the working group on Sepsis-related problems of the European Society of Intensive Care Medicine. Intensive Care Med. 1996;22:707-10.

16. Magiorakos AP, Srinivasan A, Carey RB, Carmeli Y, Falagas ME, Giske CG, et al. Multidrug-resistant, extensively drug-resistant and pandrug-resistant bacteria: an international expert proposal for interim standard definitions for acquired resistance. Clin Microbiol Infect. 2012;18:268-81.

17. Montravers P, Dupont $\mathrm{H}$, Leone M, Constantin JM, Mertes PM, Laterre PF, et al. Guidelines for management of intra-abdominal infections. Anaesth Crit Care Pain Med. 2015;34:117-30. 
18. Dupont H, Bourichon A, Paugam-Burtz C, Mantz J, Desmonts JM. Can yeast isolation in peritoneal fluid be predicted in intensive care unit patients with peritonitis? Crit Care Med. 2003;31:752-7.

19. Paugam-Burtz C, Dupont H, Marmuse JP, Chosidow D, Malek L, Desmonts JM, et al. Daily organ-system failure for diagnosis of persistent intra-abdominal sepsis after postoperative peritonitis. Intensive Care Med. 2002;28:594-8.

20. Montravers P, Dufour G, Guglielminotti J, Desmard M, Muller C, Houissa H, et al. Dynamic changes of microbial flora and therapeutic consequences in persistent peritonitis. Crit Care. 2015;19:70.

21. Harbarth S, Ferriere K, Hugonnet S, Ricou B, Suter P, Pittet D. Epidemiology and prognostic determinants of bloodstream infections in surgical intensive care. Arch Surg. 2002;137:1353-9.

22. Weinstein MP, Reller LB. Clinical importance of "breakthrough" bacteremia. Am J Med. 1984;76:175-80

23. Dupont H, Paugam-Burtz C, Muller-Serieys C, Fierobe L, Chosidow D, Marmuse JP, et al. Predictive factors of mortality due to polymicrobial peritonitis with Candida isolation in peritoneal fluid in critically ill patients. Arch Surg. 2002;137:1341-7.

24. Montravers P, Perrigault PF, Timsit JF, Mira JP, Lortholary O, Leroy O, et al. Antifungal therapy for patients with proven or suspected Candida peritonitis: Amarcand2, a prospective cohort study in French intensive care units. Clin Microbiol Infect. 2017:23:117. e111-117.e118

25. Mazuski JE, Tessier JM, May AK, Sawyer RG, Nadler EP, Rosengart MR, et al. The surgical infection society revised guidelines on the management of intra-abdominal infection. Surg Infect. 2017;18:1-76.

26. Sartelli M, Catena F, Abu-Zidan FM, Ansaloni L, Biffl WL, Boermeester MA, et al. Management of intra-abdominal infections: recommendations by the WSES 2016 consensus conference. World J Emerg Surg. 2017;12:22.

27. Fierobe L, Decre D, Muller C, Lucet JC, Marmuse JP, Mantz J, et al. Methicillin-resistant Staphylococcus aureus as a causative agent of postoperative intra-abdominal infection: relation to nasal colonization. Clin Infect Dis. 1999;29:1231-8.

28. Montravers P, Tubach F, Lescot T, Veber B, Esposito-Farese M, Seguin P, et al. Short-course antibiotic therapy for critically ill patients treated for postoperative intra-abdominal infection: the DURAPOP randomised clinical trial. Intensive Care Med. 2018;44:300-10.

Ready to submit your research? Choose BMC and benefit from:

- fast, convenient online submission

- thorough peer review by experienced researchers in your field

- rapid publication on acceptance

- support for research data, including large and complex data types

- gold Open Access which fosters wider collaboration and increased citations

- maximum visibility for your research: over $100 \mathrm{M}$ website views per year

At BMC, research is always in progress.

Learn more biomedcentral.com/submissions 